\section{The status of Indonesia's seagrass meadows}

Indonesia stores $2 \%$ of the world's blue carbon in its seagrass meadows, which are under threat from human activities like coastal development. Without a long-term, large-scale monitoring effort, the continual decline and hopeful recovery of this vital ecosystem will be very difficult to track.

Seagrass meadows are important nurseries for commercial fisheries, and also help nearby coral reefs, providing essential ecosystem services for Indonesia. The country is likely home to the world's largest seagrass meadows, storing at least $2 \%$ of the world's blue carbon. Sadly, these seagrasses are under threat.

Seagrasses in the Indo-Pacific are under-studied. The region may have already lost $40 \%$ of its seagrass meadows, but there are currently no large-scale long-term monitoring efforts to provide precise assessments. To determine the current status, historical trends, and threats to seagrasses, researchers turned to local ecological knowledge and expert scientific opinions.

A workshop was held in July 2016 to bring together 25 seagrass experts from around the country, representing academia, government, and civil society organizations. Workshop participants completed a questionnaire about seagrasses in their local area to kickstart data collection. The experts ranked threats to seagrass vulnerability and estimated uncertainty. Expert opinion was supported with a literature review.

Most experts reported a decline in the spatial extent of seagrasses in their home turf over the past five years. Many also reported declines in species richness and overall health. Coastal development and sedimentation were cited as the biggest contributors to seagrass loss. Other threats, like sand mining and oil pollution were limited to certain regions of Indonesia. Seagrass recovery was rarely reported.

The main barrier to seagrass restoration reported by the experts is a lack of knowledge about the importance of seagrasses among the country's population, and especially political leaders and funding agencies. The fact that local villages lack the legal jurisdiction to act on their own disempowers local people from being able to engage in their own conservation efforts.

Funders of ocean conservation efforts should take note of the perilous state of Indonesia's seagrass ecosystems - and especially the lack of monitoring efforts - to help combat future losses to one of the world's major contributors of blue carbon sequestration.
This is a summary of: Indonesia's globally significant seagrass meadows are under widespread threat

Accessible at: https://marxiv.org/jw6ad

Authors: Richard Unsworth, Rohani Ambo-Rappe, Benjamin Jones, Yayu La Nafie, A. Irawan, Udhi Hernawan, Abigail Moore, Leanne Cullen-Unsworth

Added to MarXiv: May 2018

Published: Science of the Total Environment, 2018

Suggested Citation: The status of Indonesia's seagrass meadows. OCTO (2018). DOI: 10.17605/OSF IO/JUK4H

See more MarXiv summaries at https://www.marxivinfo.org/ summaries

Join the MarXiv Summaries monthly newsletter at https:// oct.to/marxivsum

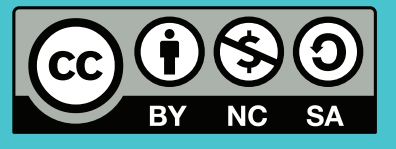

MarXiv is an ОCTO Initiative

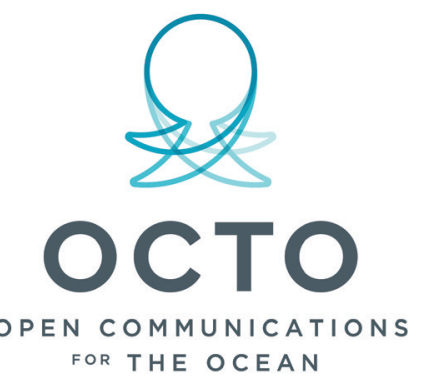

